\title{
YIELD GAP ANALYSIS OF MAJOR PULSES IN INDIA
}

\author{
N. S. Rimal ${ }^{*}$ and S. Kumar ${ }^{2}$ \\ ${ }^{1}$ Division of Agricultural Economics, Indian Agricultural Research Institute (IARI), \\ ${ }^{2}$ Indian Council of Agricultural Research (ICAR)
}

\begin{abstract}
In order to assess the nature and extent of yield gap in major pulses in India, published data from different official records were used for different time periods and comparison was made between states and India regarding yield difference of different pulses. Yield gap II was assessed with the help of data obtained from annual reports of Indian Institute of Pulses Research, Kanpur for major pulses crops. Both yield gap I and Yield gap II was examined in case of chickpea for the period of 2011-12 taking an aggregated yield data. The result revealed that most of the major pulses growing states were having lower yield of total pulses than national average while minor states showed higher yield during 2006-2012. With the positive growth in yield of individual pulses minor states were moving forward and showed potential increase in production of pulses. Yield gap II of major pulses in India showed an increase in the recent period over 2006-07. In case of chickpea frontline demonstration data for the period of 2011-12 revealed that yield gap II ranged from $7.63 \%$ in Karnataka to $24.37 \%$ in Madhya Pradesh among major chickpea producing states while this gap was $15.80 \%$ in Chattishgarh and $29.09 \%$ in Bihar among minor states. Yield gap for the same period was observed to be $28.46 \%$ in Madhya Pradesh, $28.75 \%$ in Karnataka and $28.56 \%$ in Maharashtra. These states contribute more than $50 \%$ of area share indicating tremendous untapped potential. Factors causing exploitable yield gap could be managed with effective implementation of government program along with participatory research and extension services ensured within the time frame.
\end{abstract}

Key Words: Yield gap, demonstration, pulses

\section{INTRODUCTION}

India is the largest producer, consumer and importer of pulses in the world. Despite of the diverse role of pulses in solving the problem of food and nutritional security, they are assumed as secondary crops not only in the developing world but also in India. With 3\% of the world area, India accounts for $22 \%$ of the world production of the pulses. About $67 \%$ of the global Chickpea, $72 \%$ of Pigeonpea and $38 \%$ of Lentil area falls in India, corresponding to $66 \%, 63 \%$ and $21 \%$ of the global production, respectively. Despite of this fact, the yield of the Pulses in India is much less compared to the world. During 1990s the average difference in the yield of pulses between India and World was $214 \mathrm{~kg} / \mathrm{ha}$ which in the recent decade (2000s) showed an average difference of $229 \mathrm{~kg} / \mathrm{ha}$ (FAOSTAT, 2014). Pulses in India are grown mostly in rainfed situation with less than ideal condition which may be the major cause for the lower yield. Among five major pulses, chickpea, pigeonpea and lentil are grown in around $60 \%$ of the total pulses area in India and contribute around $70 \%$ of the total pulses production during 2012-13 (GoI, 2013). Although the pulses sector in India shows increasing trend in area and production with the initiation of government incentives for the farmer through different programs (NFSM-Pulses, A3P), there is no much satisfactory improvement in the yield of the pulses crop as a whole as well as the individual pulse in India. Therefore, it always matters for the researcher and the policy makers that real potential of pulses are harvested at the farmers' field. In the real situation, however, a gap is observed between projection of the potential yield of certain crop variety 
during its evolution in the research field and obtained yield on organized farm demonstration and further with the harvested by the farmers themselves.

The yield gap is defined as the difference between the maximum-attainable yield and the farmlevel yield. There are number of empirical evidences regarding yield gap analysis of different food crops like Rice, Wheat, Maize etc. (Aggrawal, et al., 2008 and Elsamma, Job., 2006) and different oilseeds crops like Soybean, Rapeseed \& Mustard, Groundnut etc. (Jha, et al., 2011; Hall, et al., 2013 and Bhatia, et al., 2006). Yield gap analysis in the case of major pulses crops like chickpea, pigeonpea, lentil etc. are rare in the literature. However, some of the studies (Dwivedi, et al., 2013; Bhatia, et al., 2006 and Singh, et al., 2001) tried to quantify yield gap mostly of chickpea and pigeonpea in the aggregate level in India. Rapid technological change and cultivation practices used to bring variation in the yield between research station and farmers' field, quantification of which will be valuable to draw the attention of policy maker in order to evolve and implement the judicious plan and policies. Thus, this study attempts to assess the nature and extent of yield gap of major pulses in India. The study assumed the existence of gap in different individual pulses in India and major states due to the policy intervention of government of India in the pulses sector with the aim of curing mismatch between demand and supply conditions prevailing in the country.

\section{MATERIALS AND METHODS}

The present study uses potential yield, field demonstration yield and farmers' yield. The actual average yields of the farmers' field were sourced from Department of Economics and Statistics, Ministry of Agriculture and published reports. The potential yield and field demonstration yield were compiled from the Frontline Demonstration (FLD) data from published report of All India Coordinated Research Projects (AICRP) on different pulses conducted by Indian Council of Agricultural Research. The average yield of FLDs vis-à-vis farmers' field averaged for the year of 2009-2012 were compiled from the annual reports of Indian Institute of Pulses Research (IIPR), Kanpur, India. Yield obtained on research stations, demonstration plots and farmer's fields respectively were defined as the potential yield, farm yield and farmer's yield in the methodology developed by IRRI to estimate the magnitude of yield gaps. The yield gap comprises at least two components. The first component-yield gap I is the difference between research station yield and the field demonstration yield. The second component - yield gap II is the difference between the field demonstration yield and the actual average farmers' yield (Alam, 2006). The nature and extent of the yield gap in pulses in the states and India was analyzed using the following Gap I and Gap II equation in the percentage form.

Gap I: It is the gap between potential yield $\left(\mathrm{Y}_{\mathrm{P}}\right)$ of a variety and the yield in the demonstration field $\left(\mathrm{Y}_{\mathrm{df}}\right)$ i.e.

Yield Gap I $(Y G I)=\frac{(Y p-Y d f)}{Y p} \times 100 \%$

Gap II: Similarly, Yield gap II is the difference between the yield of variety in the demonstration field $\left(\mathrm{Y}_{\mathrm{df}}\right)$ and at farmers' field $\left(\mathrm{Y}_{\mathrm{ff}}\right)$, i.e.

Yield Gap II $($ YG II $)=\frac{(\text { Ydf }- \text { Yff })}{\text { Yp }} \times 100 \%$

This study made an attempt to assess the exploitable yield reservoir in case of different pulses using frontline demonstration data. But, the availability of the official record regarding frontline 
demonstration data for individual pulses crop in different states threw limitation for the analysis. Thus, with the recent data available for chickpea pertaining to the year of 2011-12, yield gap I and yield gap II were computed for major and minor states. Yield Gap II was computed for different pulses at the national level with the available data averaged for 2009-2012.

\section{RESULTS AND DISCUSSION}

\section{Comparison of yield of total pulses in India and States}

Table 1 compared the average yield of total pulses during 2007-2012 and classified eleven major pulses producing states into two groups as yield $(\mathrm{kg} / \mathrm{ha})$ more than national average and less than national average. The result shows that average yield of the total pulses during 2007-2012 in most of the states was more than national average of $786 \mathrm{~kg} /$ ha while Rajasthan and Karnataka were the states with yield less than the national average. Although the share of Rajasthan and Karnataka in terms of area was more than the minor states like Jharkhand, West Bengal, Bihar and Haryana the average yield was recorded comparatively lower. The results have shown stagnant conditions of pulses crops in their respective major producing states and have revealed the potential of minor pulses producing states in pulses development, as yield of pulse crops in their minor producing states was higher than the national average. So the appropriate policies for minor pulses producing states will have long-term implications for pulses development and production sustainability.

Table 1. Comparison of yield of total pulses in India and States (Average of 2007-2012)

\begin{tabular}{ll}
\hline Yield (kg/ha) & States \\
\hline More than National Average & $\begin{array}{l}\text { Madhya Pradesh, Uttar Pradesh, Maharashtra, Andhra Pradesh, } \\
\text { Gujarat, Jharkhand, Bihar, West Bengal, Haryana }\end{array}$ \\
Less than National Average & Rajasthan, Karnataka \\
\hline
\end{tabular}

Source: Compiled with the data from Directorate of Economics and Statistics, Department of Agriculture and Cooperation, Ministry of Agriculture, Government of India.

\section{Yield gap II of major pulses in India}

Table 2 shows the yield gap II also called as an extension gap of major pulses in India pertaining 2009 to 2012 periods. With the available information in various annual reports published by Indian Institute of Pulses Research (IIPR), Kanpur, yield gap II was assessed with prior mentioned technique. The yield gap was examined taking an average aggregated yield to remove the year to year variation. At the national level, yield gap II was recorded highest in Arhar (27.24\%) during 2009-12 period followed by lentil (23.92\%), fieldpea (21.88\%) and gram (20.88\%) (Table 2). Among major pulses yield gap II was observed less in Kharif as well as Rabi Moong at the national level during the same period. By considering yield gap II in major pulses it was found that pulses productivity could be improved by $20.45 \%$ on an average at all India level. The productivity level can be improved mainly from $27.24 \%$ in Arhar, 23.92\% in lentil and 20.88\% in gram, the major pulses cultivated in India. Since, Arhar among Kharif and gram among Rabi pulses shares more in area and production of total pulses in India the increased yield gap in both the pulses crops should be well addressed with the technology transfer to the farmers. Thus, this calls for an effective transfer mechanism of improved pulses production technologies to growers so that yield reservoir could be harvested. 
Table 2. Yield gap II of different pulses in India.

\begin{tabular}{|c|c|c|c|}
\hline Crop/Season & \multirow{2}{*}{$\begin{array}{c}\text { Yield Gap II (2009-12) } \\
\text { Percentage }(\%) \\
\end{array}$} & Crop/Season & \multirow{2}{*}{$\begin{array}{c}\text { Yield Gap II (2009-12) } \\
\text { Percentage }(\%)\end{array}$} \\
\hline Kharif & & Rabi & \\
\hline Arhar & 27.24 & Gram & 20.88 \\
\hline Moong & 17.77 & Moong & 15.38 \\
\hline \multirow[t]{4}{*}{ Urad } & 20.58 & Urad & 15.98 \\
\hline & & Lentil & 23.92 \\
\hline & & Fieldpea & 21.88 \\
\hline & Average & \multicolumn{2}{|r|}{20.45} \\
\hline
\end{tabular}

\section{Yield gap of chickpea (Gram) in the states and India}

All the chickpea growing states in India show certain gap in yield between states and all India both during 2006-07 and 2012-13 periods (Table 3). The analysis of the yield difference of chickpea in the states and India shows that Andhra Pradesh during 2006-07 was having around $240 \mathrm{~kg} / \mathrm{ha}$ more of aggregate average yields than the national average which declined to around $98 \mathrm{~kg} / \mathrm{ha}$ during 201213 periods. In case of minor chickpea producing states like Bihar, Haryana, Chattishgarh and West Bengal, the aggregated average yield of chickpea showed increasing difference in the recent years. These states were having less than national average yield during 2006-07 periods. Major chickpea producing states like Madhya Pradesh, Uttar Pradesh and Andhra Pradesh showed positive yield difference in 2012-13 whereas Karnataka and Rajasthan showed average yield marginally less than national average and Gujarat, Maharashtra and Tamil Nadu were showing increasing difference in the average yield compared to national yield. Most of the states in the recent period have recorded positive or increasing difference in the yield of chickpea compared to national average. This increased yield in the state might be the result of government program of transferring technologies like high yielding varieties, demonstration for the integrated nutrient management along with insect and pest management techniques which are crucial for the improvement of yield of chickpea crop in most of the states.

Table 3. Yield difference of chickpea in states and India during 2006-07 and 2012-13

\begin{tabular}{|c|c|c|}
\hline States & 2006-07 (kg/ha) & $2012-13$ (kg/ha) \\
\hline Andhra Pradesh & 240 & 98 \\
\hline Bihar & -27 & 381 \\
\hline Gujarat & 25 & -43 \\
\hline Haryana & -2 & 107 \\
\hline Chhattisgarh & -2 & 48 \\
\hline Karnataka & -372 & -378 \\
\hline Madhya Pradesh & 135 & 198 \\
\hline Maharashtra & -139 & -259 \\
\hline Rajasthan & 18 & -1 \\
\hline Tamil Nadu & -201 & -382 \\
\hline Uttar Pradesh & -103 & 98 \\
\hline West Bengal & -76 & 156 \\
\hline
\end{tabular}

Source: Compiled with the data from Directorate of Economics and Statistics, Department of Agriculture and Cooperation, Ministry of Agriculture, Government of India. 


\section{Yield gap of chickpea (Gram) in different states}

Data of AICRP-chickpea during 2011-12 on frontline demonstration revealed that the yield gap II for chickpea was $20 \%$ at the national level. The gap ranged from $7.63 \%$ (Karnataka) to $24.73 \%$ (Madhya Pradesh) among major chickpea growing states while this gap was $15.8 \%$ (Chattisgarh) and $29.09 \%$ in Bihar among minor chickpea growing states (Table 4). Yield gap I for the same period was observed to be $28.46 \%$ in Madhya Pradesh, 28.75\% in Karnataka and 28.56\% in Maharashtra. These states account for more than 50\% of area under chickpea indicating tremendous untapped potential. Yield gap II also reveals that the chickpea productivity at the national level could be improved by tapping the gap existed in the major states. The productivity of chickpea could be improved from 24\% in Madhya Pradesh, 21\% in Uttar Pradesh and 15\% in Maharashtra while minor states should be facilitated with concerted extension services to increase the adoption level of crop specific technologies among the chickpea growers. Front line demonstrations have successfully shown that through adoption of improved production technologies, yield of pulses in general and Moong and gram in particular can be increased by $46 \%$ and $31 \%$, respectively (Gautam et al.,2007). Yield gap I is non-exploitable which is mainly because of changes in environmental conditions. The rise in gap indicates the improvement over the technology frontiers. Yield gap II is manageable and can be bridged as it is mainly due to the difference in farmers' agronomical management practices (Lakshmanan, S. 2007). Thus, institutional and policy support to farmers is crucial for ensuring agricultural input supplies, farm credit in a holistic approach which could lead to sustainable improvement in chickpea production and productivity in particular and pulses in general. Rapid dissemination of technologies to the farmers' level is urgent and further the integrated nutrient management and plant protection provision inclusive in programs like National Food Security Mission-Pulses (NFSM-Pulses) and Pulses Production Program (A3P) should be ensured in time together with seed minikit along with extension and institutional support so that farmers could conduct field operations in time with package practices which most probably assist in improvement of overall chickpea productivity.

Table 4. Yield gap in chickpea growing states during 2011-12

\begin{tabular}{llcc}
\hline & States & Yield Gap I (\%) & Yield Gap II (\%) \\
\hline \multirow{3}{*}{ Major } & Madhya Pradesh & 28.46 & 24.37 \\
& Rajasthan & 18.72 & 14.35 \\
& Maharashtra & 28.56 & 15.72 \\
& Andhra Pradesh & 3.49 & 7.76 \\
& Uttar Pradesh & 19.02 & 21.02 \\
& Karnataka & 28.75 & 7.63 \\
\hline \multirow{3}{*}{ Minor } & Chhattisgarh & 5.47 & 15.80 \\
& Gujarat & 7.33 & 21.87 \\
& Bihar & 30.55 & 29.09 \\
& J\&K & 65.33 & 18.05 \\
\hline
\end{tabular}

Source: Published Annual report of All-India Coordinated Research Project on Chickpea (20112012) 


\section{CONCLUSION}

Comparison of the yield of the total pulses in states and all India shows that major pulses producing states like Rajasthan and Karnataka were having yield less than national average while most of the minor states were having more yield. Thus, this indicates the urgent focus on minor states for improvement in pulses production in the country. In case of chickpea, Madhya Pradesh, the major pulse producing state showed lower yield than national average. With the positive growth in yield of individual pulses minor states are moving forward and showed the potential of increasing production of pulses and such situation should be sustained with appropriate policy intervention. Data pertaining 2011-12 of frontline demonstration revealed that yield gap II ranged from 7.63\% (Karnataka) to $24.37 \%$ (Madhya Pradesh) among the major chickpea growing states while this gap was $15.80 \%$ in Chattishgarh and 29.09\% in Bihar among minor chickpea growing states. Madhya Pradesh with higher share in area and production of chickpea in the country showed around $24 \%$ of yield gap II. This shows that farmers are yet to harvest potential yield of the chickpea which could be possible with the adoption of modern and improved chickpea technologies. Yield gap I in the same period was observed 28.46\% in Madhya Pradesh, 28.76\% in Karnataka and 28.56\% in Maharashtra. These states account for around $50 \%$ share in area and production of chickpea and such gap indicates plenty of untapped potential. This also revealed that breeder for the varietal development should be linked with the extension worker in order to know the ground reality of farmers so that the recommended potential yield could be harvested in the farmers' field. Effective and rapid dissemination of technologies and their knowledge to the farmer is urgent in order to achieve this objective and further the integrated nutrient management and plant protection provision as included in the National Food Security Mission-Pulses (NFSM-Pulses) and strengthened by Accelerated Pulses Production Program (A3P) should be ensured in time with extension and institutional support.

\section{ACKNOWLEDGEMENT}

I am obliged to express my deep sense of gratitude and indebtedness to all the members of my Advisory Committee for their scrupulous guidance, unrelenting encouragement, Co-operative attitude and productive criticism during the course of investigation and preparation of the manuscript. I also acknowledge and thank Dean and Joint Director (Education) of Indian Agricultural Research Institute and Department of Agricultural Research and Education, Government of India for providing the financial assistance in the form of Nepal-Aid Fund Scholarship Scheme through Embassy of India, Kathmandu, Nepal.

\section{REFERENCES CITED}

Aggarwal, P. K., K. B., Hebbar, M. V., Venugopalan, S., Rani, A Bala, et al., 2008. Quantification of Yeld Gaps in Rain-fed Rice, Wheat, Cotton and Mustard in India. Global Theme on Agroecosystems, Report no. 43, International Crops Research Institute for the Semi-Arid Tropics (ICRISAT), Andhra Pradesh, India

Alam, M. 2006. Factors Affecting Yield Gap and Efficiency in Rice Productions in some Selected Areas of Bangladesh. Ph.D. Thesis (Unpublished), Department of Economics, Jahangir Nagar University, Bangladesh.

Bhatia, V. S., P., Singh, S. P., Wani, A. V. R. Kesava Rao, and K. Srinivas. 2006. Yield Gap Analysis of Soybean, Groundnut, Pigeonpea and Chickpea in India using Simulation Modeling. Global 
Theme on Agro-ecosystems, Report no. 31. International Crops Research Institute for the SemiArid Tropics (ICRISAT), Andhra Pradesh, India.

Dwivedi, S. V., R. K. Anand, and M. P. Singh.2013. Varietal Performance of Oilseeds and Pulses at Farmers' Field in Vindhyan Zone under Rainfed Condition. TECHNOFAME-A Journal of Multidisciplinary Advance Research, 2 (1):25-29.

Elsamma, J. 2006. Yield Gap of Rice in Alppuzha District of Kerala. Journal of Tropical Agriculture, 44 (1-2): 88-90.

FAOSTAT, 2014. Retrieved on 17 May 2014 from http:/faostat3.fao.org/faostat-gateway/go/to/ download/Q/QC/E.

Gautam, U. S., D. K. Paliwal, and S. Naberia. 2007. Improvement in Livelihood Security for Small and Marginal Farmers through Front Line Demonstrations on Oilseed and Pulses Crops in Central India. Indian Research Journal of Extension Education, 7 (1):1-5.

GoI, 2013. Agricultural Statistics at a Glance. Directorate of Economics and Statistics, Department of Agriculture and Cooperation, Ministry of Agriculture, Government of India.

Hall, A. J., Feoli, C., J. Ingaramo, and M. Balzarini. 2013. Gaps between Farmer and Attainable Yields across Rainfed Sunflower Growing Regions of Argentina. Field Crop Research, 143: 119-129

Jha, G. K., R. R., Burman, S. K.,Dubey, and G. Singh. 2011. Yield Gap Analysis of Major Oilseeds in India, 6 (2): 209-216.

Lakshmanan, S. 2007. Yield Gaps in Mulberry Sericulture in Karnataka: An Econometric Analysis. Indian Journal of Agricultural Economics, 62 (4):623-636

Singh, N., Kaur, H. and Singh, R. 2001. A Diagnosis on Area, Productivity and Production of Pulses in India. Indian Journal of Agricultural Economics, 57(3): 393-394.

Singh, R. P. 2012. Status Paper on Pulses. Retrieved 11 January 2014, from http://nfsm.gov.in/Pulses/ Status.pdf 